\title{
Analisis Video Likes To Followers Ratio Tiktok Pada 5 Aplikasi Nonton Streaming Anime Terbaik
}

\author{
Ngakan Made Satria Puspadana \\ Satriapuspadana66@gmail.com
}

\begin{abstract}
TikTok is a Chinese social network and music video platform launched in September 2016 by Zhang Yiming, the founder of Toutiao. TikTok allows users to create 15-second videos accompanied by music, filters, and several other creative features. In Indonesia itself, Tiktok has started to be busy in 2018. Currently, there are 92.2 million Tiktok users in Indonesia, as of July 2021. This application is very popular and has been used by millions of users around the world. The large number of active TikTok users in Indonesia can certainly provide an opportunity for brands to make the TikTok platform a social media marketing platform. There are also 5 Best Anime Streaming Apps that use TikTok as a marketing platform, namely: Crunchyroll, iQiyi, Netflix, Iflix and Hulu. The purpose of this study is to calculate the credibility of the TikTok account performance in the Top 5 Best Anime Streaming Applications. The method used for this research is quantitative exploratory method. The results of this study indicate that Crunchyroll is ranked first and has good account performance credibility.
\end{abstract}

\begin{abstract}
ABSTRAK
TikTok adalah sebuah jaringan sosial dan platform video musik Tiongkok yang diluncurkan pada September 2016 oleh Zhang Yiming, pendiri Toutiao. TikTok memungkinkan penggunanya membuat video berdurasi 15 detik yang disertai dengan musik, filter, dan beberapa fitur kreatif lainnya. Di Indonesia sendiri, Tiktok sudah mulai ramai digunakan pada tahun 2018. Saat ini ada 92,2 juta pengguna tiktok di Indonesia, dihitung pada Juli 2021. Aplikasi ini sangat populer dan telah digunakan oleh jutaan pengguna di seluruh dunia. Maraknya jumlah pengguna TikTok yang aktif di Indonesia tentu dapat memberikan peluang bagi brand untuk menjadikan platform TikTok sebagai platform social media marketing. Ada juga 5 Aplikasi Nonton Streaming Anime Terbaik yang memanfaatkan TikTok sebagai platform marketing, yaitu: Crunchyroll, iQiyi, Netflix, Iflix dan Hulu. Tujuan dari penelitian ini yaitu untuk menghitung kredibilitas dari performa akun TikTok Top 5 Aplikasi Nonton Streaming Anime Terbaik. Metode yang digunakan untuk penelitian ini yaitu metode eksploratif kuantitatif. Hasil dari penelitian ini menunjukan bahwa Crunchyroll mendapatkan peringkat pertama dan memiliki kredibilitas performa akun yang baik.
\end{abstract}

Keywords: Credibility Account TikTok; Social Media Marketing; Video Likes to Followers Ratio; TikTok Booming; Best Anime Streaming Application. 


\section{PENDAHULUAN}

Pada era revolusi industri 4.0 yang sudah sangat maju dan berkembang dengan pesat seperti saat ini, teknologi digital pun juga berkembang dengan sangat pesat dan tak terduga. Salah satu perkembangan teknologi yang paling kita rasakan kehadirannya adalah internet. Internet membuat semuanya terlihat lebih mudah, dari yang awalnya serba rumit, sekarang dapat diselesaikan dengan sangat mudah hanya dengan sekali klik saja. Segala hal yang dahulu dianggap susah bahkan cenderung mustahil pun kini bisa dilakukan melalui internet. Teknologi digital saat ini seperti menjadi salah satu hal pokok yang sangat penting bagi kehidupan umat millenial. Pada era ini banyak sekali terdapat hal-hal yang dapat dilakukan dengan teknologi, salah satu contohnya adalah untuk berkreasi dan berkomunikasi.

Media sosial tidak hanya digunakan sebagai alat untuk berkomunikasi dan berinteraksi, tetapi juga sebagai alat ekspresi diri (self expression) dan pencitraan diri (self branding). Seiring dengan kemajuan teknologi, maka banyaknya media yang dapat digunakan manusia untuk dijadikan alat dalam berkomunikasi, demikian pula dengan media sosial diantaranya untuk berbagi pesan dengan banyak pengguna media sosial itu sendiri, yaitu berupa berita (informasi), gambar (foto), dan juga video. Media sosial pun juga merupakan wadah yang mampu menciptakan bermacam bentuk komunikasi dan pemberian berbagai macam informasi bagi semua kalangan masyarakat tanpa memandang kalangan mana maupun statusnya apa. Dengan media social juga setiap individu dapat berkomunikasi dan berbagi informasiinformasi kepada semua kalangan masyarakat (Cakra 2020).

Anime merupakan sebutan film animasi atau kartun yang berasal dari Jepang. Jika kamu ingin nonton anime subtitle indonesia lengkap atau lainnya, maka bisa mengakses beberapa aplikasi atau situs legal di bawah ini. Sayangnya di Indonesia masih banyak yang tidak mengetahui hal tersebut dan lebih memilih untuk menonton anime lewat situs ilegal. Bukan hanya karena alasan ketidaktahuan, tidak sedikit yang berlasan tidak berkenan untuk melakukan langganan berbayar. Situs bermunculan dan menjadi andalan orang-orang saat ingin mencari film anime terbaru, sebut saja Samehada, Oplovers, dan lain-lain. Situs-situs itu kerap diblokir dan kerap banyak iklan yang menggangu, membuat penonton film gratisan jadi kesulitan saat ingin mencari hiburan. Adapun aplikasi yang bisa kamu unduh untuk menonton anime , contohnya seperti : Crunchyroll, iQiyi, Netflix, Iflix, dan Hulu.(“Inilah 5 Aplikasi Nonton Streaming Anime Terbaik, Dijamin Legal," n.d.)

Penelitian ini menggunakan metode eksploratif kuantitatif, dan akan menghitung menggunakan rasio-rasio yang ada pada TikTok. Pada penelitian (I Putu Hendika Permana and Ni Putu Suci Meinarni 2021) menjelaskan bahwa terdapat 17 rasio yang ada pada sosial media TikTok dan relevan digunakan sebagai media ukur kredibilitas akun yang ada. Penelitian ini hanya berfokus untuk menghitung kredibilitas Video Likes to Followers Ratio pada 5 Aplikasi Nonton Streaming Anime Terbaik. Adapun 5 Aplikasi Nonton Streaming Anime Terbaik diantaranya : Crunchyroll, iQiyi, Netflix, Iflix, dan Hulu ("Inilah 5 Aplikasi Nonton Streaming Anime Terbaik, Dijamin Legal," n.d.). Tujuan dari penelitian ini adalah mengetahui kredibilitas performa dari akun TikTok 5 Aplikasi Nonton Streaming Anime Terbaik menggunakan Video Likes to Followers Ratio. 


\section{TINJAUAN PUSTAKA}

Kehidupan manusia pada era revolusi industri 4.0 ini berkembang sangatlah pesat. Hal tersebut terlihat dari banyaknya media baru yang kini mulai muncul dan diminati oleh masyarakat luas baik itu di dalam negeri maupun di luar negeri. Contoh media baru yang muncul dan saat ini berkembang dengan pesat di Indonesia yakni TikTok, Instagram, Youtube, dan lain sebagainya. Namun, diantara berbagai media baru tersebut, media yang kini sedang banyak di gandrungi oleh masyarakat Indonesia adalah Tiktok.(Cakra 2020)

Aplikasi Tiktok merupakan suatu bentuk media baru yang berfungsi untuk menyediakan dukungan berupa fitur edit seperti lagu dan efek pada wajah dalam pembuatan video berdurasi 30-60 detik.(Ruth and Candraningrum 2020). TikTok menjadi salah satu aplikasi yang paling banyak digunakan di dunia saat ini. Perusahaan baru saja mengumumkan sebuah pencapaian baru telah memiliki 1 miliar lebih pengguna aktif bulanan. TikTok bergabung dengan platform media sosial lama seperti Facebook, YouTube, WhatsApp, dan Instagram yang telah memiliki 1 miliar pengguna bulanan pada 2018 silam.(Novina Putri Bestari 2021).

Tentu saja ada penyebab mengapa TikTok begitu memikat para generasi muda. Hal tersebut dipercaya karena TikTok menawarkan fitur unik dan belum pernah ada sebelumnya, seperti pustaka musik yang luas, fitur countdown sebelum video direkam, stiker untuk mendukung penampilan di depan layar jadi makin unik, serta ragam filter yang bisa disesuaikan dengan irama musik dan video. Fitur-fitur tersebut itulah yang tidak dimiliki oleh para pesaing.

Aspek keberhasilan TikTok lainnya yang layak untuk diamati adalah investasi besar-besaran di bidang teknologi. Pengguna TikTok pasti tidak asing lagi dengan berbagai fitur teknologi canggil yang ditawarkan oleh aplikasi asal Tiongkok tersebut. Seakan tidak ingin setengahsetengah, TikTok menghadirkan berbagai fitur baru yang menjadi angin segar bagi para kreator konten di seluruh dunia.(Iwan Supriyatna 2021).

TikTok dirasakan memiliki kekuatan ataupun pengaruh dalam industri, sehingga menimbulkan kualitas akun yang menentukan strata maupun kredibilitas pemilik akun. Kredibilitas akun TikTok merupakan suatu hal yang cukup penting untuk berbagai kepentingan. Kredibilitas sebuah akun TikTok dapat diukur dari tingkat performa yang dihasilkan secara matematis. Dalam mengukur performa diperlukan skala pengukuran yang tertuang ke dalam rasio. 


\section{METODE PENELITIAN}

Penelitian ini menggunakan metode eksploratif kuantitatif untuk mengetahui kredibilitas dari performa akun TikTok 5 aplikasi nonton streaming anime terbaik. Penelitian tipe eksploratif bertujuan untuk memperdalam pengetahuan dan mencari ide-ide baru mengenai suatu gejala tertentu, untuk merumuskan masalah secara lebih terperinci atau mengembangkan hipotesis bukan menguji hipotesis(Mudjiyanto 2018).

Tujuan dari penelitian ini yaitu mengetahui nilai kredibillitas dari performa akun TikTok 5 aplikasi nonton streaming anime terbaik. Berikut adalah langkah-langkah yang harus dilakukan.

\section{Melakukan Eksplorasi Pada Website Untuk Menentukan Objek yang Akan Dianalisa.}

Eksplorasi ini dilakukan untuk mendapatkan informasi mengenai objek yang akan diteliti. Setelah eksplorasi selesai dilakukan, sehingga ditemukan nama-nama aplikasi streaming anime terbaik yang akan dijadikan objek analisa. Langkah selanjutnya yaitu mencari nama akun TikTok dari masing-masing aplikasi streaming. Pastikan semuanya memiliki akun pada aplikasi sosial media TikTok.

\section{Menghitung Nilai Rata-Rata Variable Dari 5 aplikasi nonton streaming anime terbaik}

Pada langkah ini, peneliti menghitung nilai variable video likes dan variable followers. Variabel Penelitian adalah sebuah konsep yang mempunyai nilai yang bervariasi. Dari nilai variabel tersebut dapat dibedakan menjadi empat tingkatan skala yaitu rasio, ordinal, nominal dan internal(Rangkuti 2015). Untuk menghitung nilai rata-rata dari variabel video comments dan variabel video views yaitu dengan cara mengambil minimal 10 postingan kemudian di hitung sehingga menemukan nilai rata-rata dari masing-masing variabel.

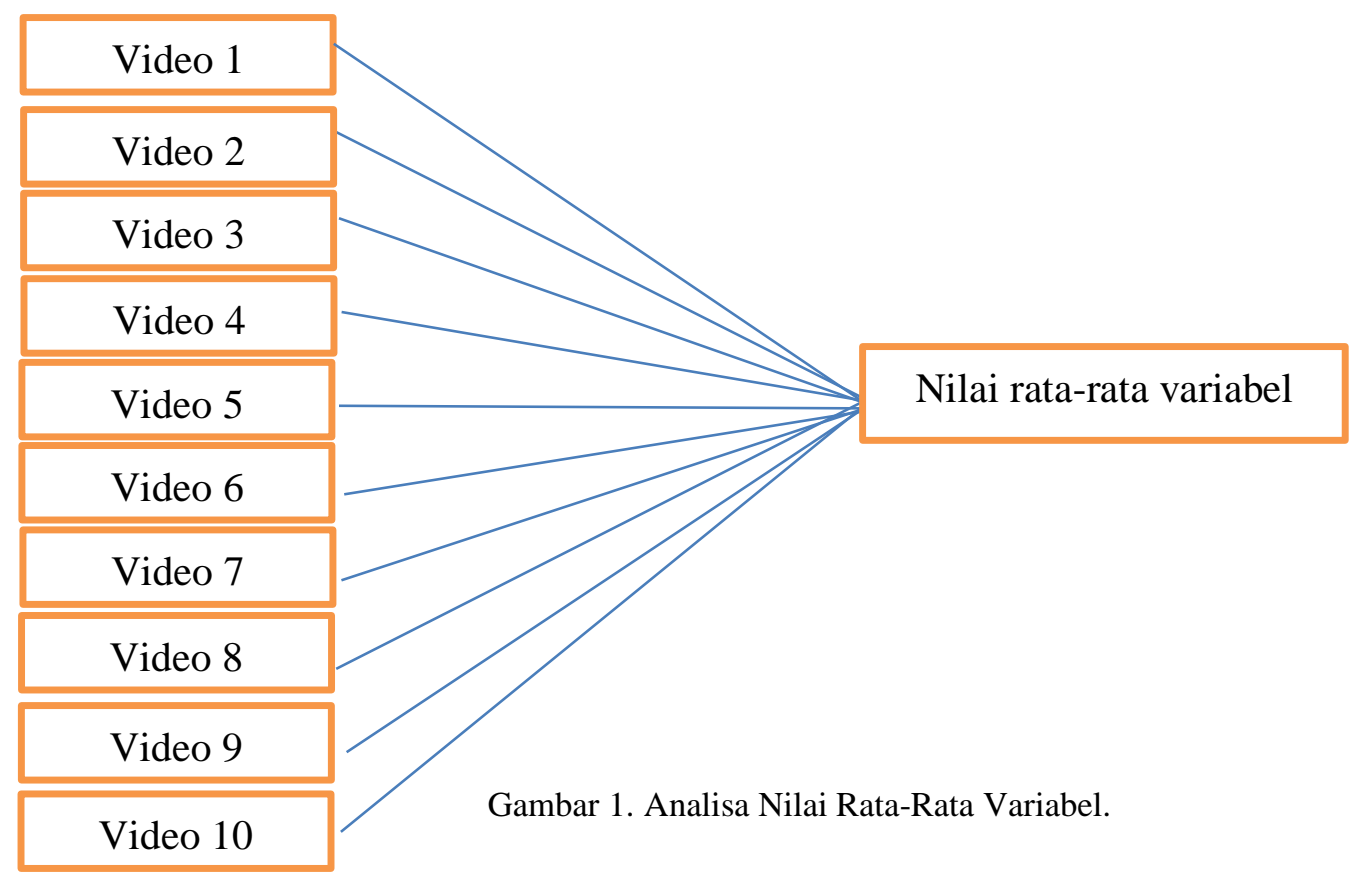




\section{Menghitung Nilai Kredibilitas Rasio}

Untuk menghitung nilai kredibilitas dari video likes to follower ratio, peneliti menggunakan cara membagi nilai variabel pertama dengan nilai variabel kedua. Jika video likes memiliki nilai 100 dan followers memiliki nilai 200, maka cara menghitungnya yaitu $100: 200=0,5$. Dengan begitu nilai dari video likes to followers ratio adalah 0,5.

\section{Menentukan Peringkat Pada Akun TikTok}

Pada penentuan peringkat perlu melihat karakteristik dari rasio yang diteliti. Jika karakteristik rasio rendah, maka objek yang memiliki nilai terendah akan mendapatkan angka 5 dan objek yang memiliki nilai tertinggi akan mendapatkan angka 1. Namun jika rasio memiliki karakteritik tinggi maka objek yang mendapatkan nilai tinggi akan mendapatkan angka 5 dan objek yang mendapatkan nilai terendah akan mendapatkan angka 1. Setelah mendapatkan hasil kredibilitas ratio maka dapat disimpulkan objek yang mana mendapatkan peringkat 1 sampai dengan peringkat 5 . 


\section{HASIL DAN PEMBAHASAN}

Akun TikTok dari 5 aplikasi nonton streaming anime terbaik, diantaranya:

\section{Crunchyroll}

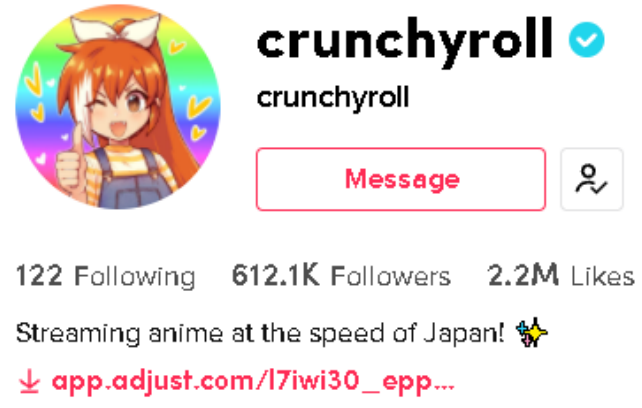

Gambar 1. Akun TikTok crunchyroll

Sumber: https://www.tiktok.com/@ crunchyroll (akses pada 20-10-2021)

\section{2. iQiyi}

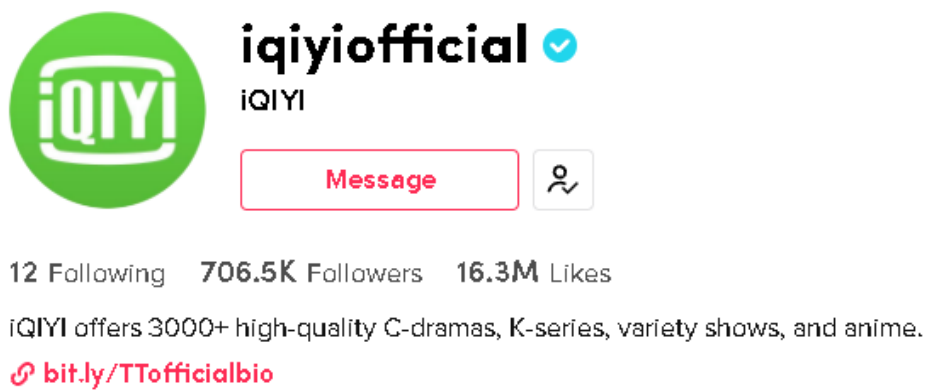

Gambar 2. Akun TikTok iqiyi

Sumber: https://www.tiktok.com/@iqiyiofficial (akses pada 20-10-2021) 


\section{Netflix}

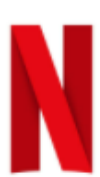

\section{netflix}

Netflix

$$
\text { Message }
$$

368 Following

20.7M Followers

316.7 M Likes

this is a Sae-Byeok fan account

ค bit.ly/2Y9JgOr

Gambar 3. Akun TikTok netflix

Sumber: https://www.tiktok.com/@netflix (akses pada 20-10-2021)

4. Iflix

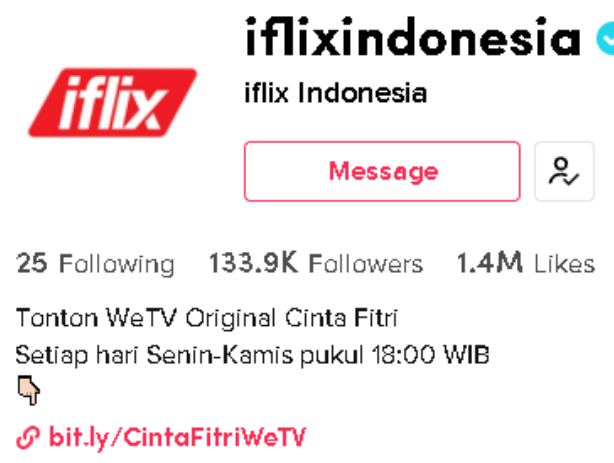

Gambar 4. Akun TikTok iflix

Sumber: https://www.tiktok.com/@iflixindonesia (akses pada 20-10-2021)

\section{Hulu}

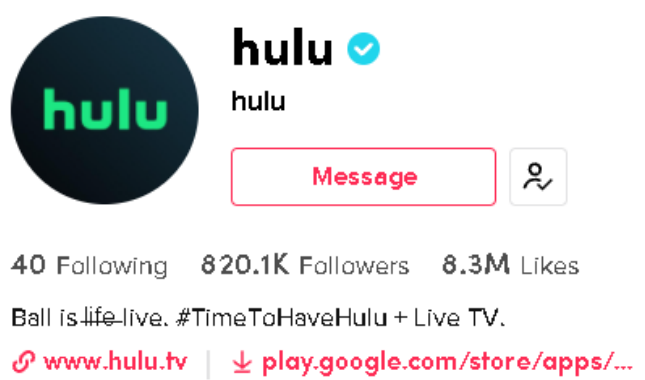

Gambar 5. Akun TikTok hulu

Sumber: https://www.tiktok.com/@hulu (akses pada 20-10-2021) 
Dari kelima Akun TikTok 5 aplikasi nonton streaming anime terbaik, peneliti menemukan nilai dari masing-masing variabel yang ada untuk menghitung rasio video likes to followers dari setiap akun. Pada akun TikTok terdapat 7 variabel, diantaranya yaitu:

1. Likes

2. Followers

3. Following

4. Video Likes

5. Video Comments

6. Video Share

7. Video Views

Dari ketujuh variabel tersebut peneliti hanya fokus untuk menemukan hasil dari 2 variabel, yaitu:

1. Video Likes

2. Followers

Dari kedua variabel tersebut kemudian dianalisa sehingga menemukan nilai rata-rata dari variabel video likes to followers. Untuk menghitung nilai rata-rata dari variabel video likes to followers yaitu dengan cara mengambil minimal 10 postingan kemudian di hitung sehingga menemukan nilai rata-rata dari masing-masing variabel. Berikut merupakan tabel nilai ratarata dari masing-masing aplikasi nonton streaming anime terbaik, yaitu:

Tabel 1. Analisa Nilai Rata-Rata Variabel video likes to followers Akun Crunchyroll.

\begin{tabular}{|c|c|c|}
\hline No & Video like & Follower \\
\hline 1 & 2,802 & 548,300 \\
\hline 2 & 132,700 & 548,300 \\
\hline 3 & 444,800 & 548,300 \\
\hline 4 & 12,500 & 548,300 \\
\hline 5 & 51,700 & 548,300 \\
\hline 6 & 47,500 & 548,300 \\
\hline 7 & 8,572 & 548,300 \\
\hline 8 & 45,500 & 548,300 \\
\hline 9 & 31,300 & 548,300 \\
\hline 10 & 42,000 & 548,300 \\
\hline Total & $\mathbf{8 1 , 9 3 7}$ & $\mathbf{5 4 8 , 3 0 0}$ \\
\hline
\end{tabular}

Sumber: Pengolah Data Excel (Analisa dilakukan pada tanggal 12-10-2021) 
Tabel 2. Analisa Nilai Rata-Rata Variabel video likes to followers Akun iQiyi.

\begin{tabular}{|c|c|c|}
\hline No & Video like & Follower \\
\hline 1 & 39,900 & 695,000 \\
\hline 2 & 29,000 & 695,000 \\
\hline 3 & 10,400 & 695,000 \\
\hline 4 & 71 & 695,000 \\
\hline 5 & 56 & 695,000 \\
\hline 6 & 54 & 695,000 \\
\hline 7 & 91 & 695,000 \\
\hline 8 & 80 & 695,000 \\
\hline 9 & 228 & 695,000 \\
\hline 10 & 108 & 695,000 \\
\hline Total & $\mathbf{7 , 9 9 9}$ & $\mathbf{6 9 5 , 0 0 0}$ \\
\hline
\end{tabular}

Sumber: Pengolah Data Excel (Analisa dilakukan pada tanggal 12-10-2021)

Tabel 3. Analisa Nilai Rata-Rata Variabel video likes to followers Akun Netflix.

\begin{tabular}{|c|c|c|}
\hline No & Video like & Follower \\
\hline 1 & 16,100 & $20,600,000$ \\
\hline 2 & 40,000 & $20,600,000$ \\
\hline 3 & 8,818 & $20,600,000$ \\
\hline 4 & 16,400 & $20,600,000$ \\
\hline 5 & 143,300 & $20,600,000$ \\
\hline 6 & 7,955 & $20,600,000$ \\
\hline 7 & 73,700 & $20,600,000$ \\
\hline 8 & 119,100 & $20,600,000$ \\
\hline 9 & 825,400 & $20,600,000$ \\
\hline 10 & 17,400 & $20,600,000$ \\
\hline Total & $\mathbf{1 2 6 , 8 1 7}$ & $\mathbf{2 0 , 6 0 0 , 0 0 0}$ \\
\hline
\end{tabular}

Sumber: Pengolah Data Excel (Analisa dilakukan pada tanggal 12-10-2021) 
Tabel 4. Analisa Nilai Rata-Rata Variabel video likes to followers Akun Iflix.

\begin{tabular}{|c|c|c|}
\hline No & Video like & Follower \\
\hline 1 & 39 & 133,600 \\
\hline 2 & 1,073 & 133,600 \\
\hline 3 & 3,188 & 133,600 \\
\hline 4 & 830 & 133,600 \\
\hline 5 & 499 & 133,600 \\
\hline 6 & 3,352 & 133,600 \\
\hline 7 & 486 & 133,600 \\
\hline 8 & 4,589 & 133,600 \\
\hline 9 & 571 & 133,600 \\
\hline 10 & 3,661 & 133,600 \\
\hline Total & $\mathbf{1 8 2 9}$ & $\mathbf{1 3 3 , 6 0 0}$ \\
\hline
\end{tabular}

Sumber: Pengolah Data Excel (Analisa dilakukan pada tanggal 12-10-2021)

Tabel 5. Analisa Nilai Rata-Rata Variabel video likes to followers Akun Hulu.

\begin{tabular}{|c|c|c|}
\hline No & Video like & Follower \\
\hline 1 & 580 & 819,500 \\
\hline 2 & 393 & 819,500 \\
\hline 3 & 277 & 819,500 \\
\hline 4 & 629 & 819,500 \\
\hline 5 & 228 & 819,500 \\
\hline 6 & 180 & 819,500 \\
\hline 7 & 195 & 819,500 \\
\hline 8 & 184 & 819,500 \\
\hline 9 & 255 & 819,500 \\
\hline 10 & 212 & 819,500 \\
\hline Total & $\mathbf{3 1 3}$ & $\mathbf{8 1 9 , 5 0 0}$ \\
\hline
\end{tabular}

Sumber: Pengolah Data Excel (Analisa dilakukan pada tanggal 12-10-2021)

Setelah menghitung nilai rata-rata tersebut, maka akan menemukan hasil akhir nilai rata-rata dari variabel video likes to followers

Tabel 6. Nilai Variabel Pada Akun TikTok 5 aplikasi nonton streaming anime terbaik.

\begin{tabular}{|c|c|c|c|c|c|}
\hline Variable & Crunchyroll & iQiyi & Netflix & Iflix & Hulu \\
\hline Video Likes & 81,937 & 7999 & 126817 & 1829 & 313 \\
\hline Followers & 548300 & 695000 & 20600000 & 133600 & 819500 \\
\hline
\end{tabular}

Sumber: Pengolah Data Excel (Analisa dilakukan pada tanggal 12-10-2021)

Pada akun TikTok terdapat 17 rasio relevan yang digunakan untuk mengukur kredibilitas pada masing-masing akun. Namun pada penelitian kali ini hanya berfokus untuk menghitung Video Likes to Followers. Untuk menghitung kredibilitas dari masing-masing akun TikTok setiap 
aplikasi nonton streaming, peneliti menghitung dengan cara: variabel 1 akan dibagi dengan variabel 2 , sehingga ditemukan hasil analisa dari rasio tersebut.

Tabel 7. Hasil Perhitungan Rasio Akun TikTok

\begin{tabular}{|c|c|c|c|c|c|c|}
\hline No & RATIO & Crunchyroll & iQiyi & Netflix & Iflix & Hulu \\
\hline 1 & $\begin{array}{c}\text { Video Likes to Followers } \\
\text { Ratio }\end{array}$ & 0.149438993 & 0.011509065 & 0.00615618 & 0.013688623 & 0.000382306 \\
\hline
\end{tabular}

Sumber: Pengolah Data Excel (Analisa dilakukan pada tanggal 12-10-2021)

Video Likes to Followers Ratio memiliki karakteristik yang tinggi, artinya semakin tinggi nilai yang dihasilkan maka semakin baik kredibilitas dari performa akun tersebut. Untuk memberikan peringkat pada masing-masing Aplikasi nonton streaming, peneliti memberikan angka 5 kepada aplikasi yang mendapatkan nilai tertinggi dan angka 1 untuk aplikasi yang mendapatkan nilai terendah. Berikut merupakan tabel urutan nilai yang dihasilkan oleh masingmasing aplikasi nonton streaming.

Tabel 8. Nilai Rasio Akun TikTok 5 aplikasi nonton streaming anime terbaik.

\begin{tabular}{|l|c|l|l|l|l|}
\hline \multirow{2}{*}{ RATIO } & \multicolumn{4}{|c|}{ NILAI } \\
\cline { 2 - 6 } & Crunchyroll & iQiyi & Netflix & Iflix & Hulu \\
\hline Video Likes to Followers Ratio & 5 & 3 & 2 & 4 & 1 \\
\hline
\end{tabular}

Sumber: Pengolah Data Excel (Analisa dilakukan pada tanggal 12-10-2021)

Dari Tabel Nilai Rasio Akun TikTok 5 aplikasi nonton streaming anime terbaik dapat disimpulkan bahwa Crunchyroll mendapatkan nilai tertinggi untuk rasio Video Likes to Followers. Sedangkan akun TikTok Hulu mendapatkan nilai terendah untuk rasio ini. Jadi, pada penelitian ini Crunchyroll memiliki tingkat kepopuleran dan performa yang lebih baik dibandingkan dengan aplikasi nonton streaming yang lainnya.

\section{KESIMPULAN}

Tujuan dari penelitian ini adalah untuk mengetahui tingkat kepopuleran dan performa dari akun TikTok 5 aplikasi nonton streaming anime terbaik menggunakan Video Likes to Followers Ratio. 5 Aplikasi Nonton Streaming tersebut diantaranya: Crunchyroll, iQiyi, Netflix, Iflix, dan Hulu. Dari kelima aplikasi streaming tersebut dapat disimpulkan bahwa:

1. Peringkat pertama diraih oleh aplikasi Crunchyroll dengan nilai tertinggi yaitu 0.149438993

2. Peringkat kedua diraih oleh aplikasi Iflix dengan nilai 0.013688623

3. Peringkat ketiga diraih oleh aplikasi iQiyi dengan nilai 0.011509065

4. Peringkat keempat diraih oleh aplikasi Netflix dengan nilai 0.00615618

5. Peringkat kelima diraih oleh aplikasi Hulu dengan nilai terendah yaitu 0.000382306 


\section{DAFTAR PUSTAKA}

Cakra, Satria. 2020. "Dampak Tik-Tok Pada Generasi Sosial Millenial." Kumparan. https://kumparan.com/satria-cakra/dampak-tik-tok-pada-generasi-sosial-millenial1v1sLqjPUCP/full.

I Putu Hendika Permana, and Ni Putu Suci Meinarni. 2021. "Ratio Analysis on Tiktok (Social Media) for Qualitative Research Using Explorative Methods." Jurnal Ekonomi \& Bisnis JAGADITHA 8 (1): 30-38. https://doi.org/10.22225/jj.8.1.2944.30-38.

“Inilah 5 Aplikasi Nonton Streaming Anime Terbaik, Dijamin Legal.” n.d.

Iwan Supriyatna. 2021. “Tiktok-Raup-Hampir-2-Miliar-Pengguna-Kalahkan-MedsosLainnya."

Mudjiyanto, Bambang. 2018. "Tipe Penelitian Eksploratif Komunikasi." Jurnal Studi Komunikasi Dan Media 22 (1): 65. https://doi.org/10.31445/jskm.2018.220105.

Novina Putri Bestari. 2021. "Tiktok-Jadi-Ancaman-Serius-Bagi-Facebook-WhatsappYoutube."

Rangkuti, Freddy. 2015. "Pengertian Variabel Penelitian Menurut Para Ahli Dan Umum Serta Jenisnya.” April 2015. https://www.sumberpengertian.id/pengertian-variabel-penelitian.

Ruth, Debra, and Diah Ayu Candraningrum. 2020. "Pengaruh Motif Penggunaan Media Baru Tiktok Terhadap Personal Branding Generasi Milenial Di Instagram." Koneksi. https://doi.org/10.24912/kn.v4i2.8093. 